\title{
Nota / Note \\ CÁDMIO E A ATIVIDADE DE PEROXIDASE DURANTE A GERMINAÇÃO DE SEMENTES DE FEIJOEIRO
}

\author{
Celso Rossi ; Giuseppina Pace Pereira Lima* \\ Depto. de Química e Bioquímica - Instituto de Biociências/UNESP, C.P. 510 - CEP: 18618-000 - Botucatu, SP. \\ *Autor correspondente <gpplima@ibb.unesp.br>
}

RESUMO: Sementes de feijoeiro cv. Carioca, foram germinadas no escuro em diferentes concentrações de cádmio (1, 2, 5 e $\left.10 \mu \mathrm{mol} \mathrm{L}^{-1}\right)$ e coletadas após 24, 48, 72 e 96 horas com o objetivo de verificar se a atividade da peroxidase, poderia ser utilizada como marcador bioquímico de estresse promovido pelo cádmio. Observaram-se alterações na atividade específica da peroxidase (EC 1.11.1.7) tanto nos cotilédones como nas raízes, em função do tempo de exposição das sementes nas diferentes concentrações de cádmio. A enzima peroxidase (EC 1.11.1.7) pode ser usada como um indicador de estresse causado pelo cádmio durante a germinação de sementes de feijão, indicando possíveis injúrias causadas nas sementes pelo metal.

Palavras-chave: Phaseolus vulgaris, peroxidase, cádmio, sementes

\section{CADMIUM AND THE ACTIVITY OF PEROXIDASE DURING BEAN SEED GERMINATION}

\begin{abstract}
Seeds of common bean seeds cv. Carioca were germinated in the dark in different concentrations of cadmium $\left(1,2,5\right.$ and $\left.10 \mu \mathrm{mol} \mathrm{L}^{-1}\right)$ and collected after 24, 48, 72 and 96 hours with the objective of verifying if theperoxidase activity could be used as a biochemical marker of stress induced by cadmium. Alterations in the peroxidase activity (EC 1.11.1.7) were oberved in the cotyledons as well as in roots, as a function of the exhibition time of seeds in different cadmium concentrations. This enzyme can be used as a stress marker caused by cadmium during bean seed germination as an indicative of possible injure of the seeds by this metal.
\end{abstract}

Key words: Phaseolus vulgaris, peroxidase, cadmium, seeds

\section{INTRODUÇÃO}

Teores fitotóxicos de metais não são ocasionalmente encontrados em solos sob condições naturais, mas podem ser originados freqüentemente de zona industrial e atividades agrícolas; metais como Zn, $\mathrm{Cu}$ e Cd são amplamente difundidos e podem aparecer em altos níveis no solo (Castillo, 1992).

O termo peroxidase (POD) inclui grupo de enzimas (EC 1.11.1.7) capazes de catalisar a oxidação de componentes celulares, tais como $\mathrm{H}_{2} \mathrm{O}_{2}$ ou peróxidos orgânicos (Kvaratskhelia et al., 1997). Em plantas, a ação desse grupo de enzimas constitui proteção antioxidativa. A atividade de peroxidase pode aumentar em plantas submetidas a diversos tipos de estresse (Siegel, 1993).

Singh et al. (1991) analisando o efeito do cádmio em vegetais aquáticos, relataram que, quando as plantas são expostas à este elemento, ocorre um desarranjo no desenvolvimento e na diferenciação celular no estágio juvenil e no crescimento, provocando portanto, estresse nestas plantas, o que provavelmente afeta diretamente a atividade de peroxidases.

Sob condições de estresse, as plantas tendem a aumentar a atividade da peroxidase e às vezes, é a primeira enzima a ter atividade alterada, independentemente do substrato utilizado ou do estresse aplicado (Siegel, 1993).

A peroxidase pode ser tomada como um marcador bioquímico de estresse resultante tanto de fatores bióticos como de abióticos (Lima et al., 1999). Gaspar (1986) afirmou que a peroxidase parece ser a molécula chave de adaptação das plantas, ou de algum de seus órgãos separadamente, às mudanças do meio ambiente. De acordo com Markkola et al. (1990), a atividade da peroxidase em tecidos vegetais é usada como um indicador não específico de estresse causado por agentes poluentes, como metais pesados.

A peroxidase foi utilizada como bioindicador da fitotoxidade de cádmio em plantas de aguapé por Ribeiro et al. (1995), onde os autores observaram que a atividade da enzima aumentou nas folhas em função da concentração de cádmio na solução e do tempo de exposição. Nas raízes, a atividade apresentou valores maiores nos tratamentos com $10 \mu \mathrm{mol}$ quando comparados com os tratamentos de 0 e $20 \mu \mathrm{mol}$ de cádmio.

$O$ presente trabalho teve por objetivo estudar a atividade da peroxidase (possível indicador bioquímico de estresse promovido por metais pesados) durante a germinação de sementes feijão, na presença de cádmio na solução de embebição. 


\section{MATERIAL E MÉTODOS}

O experimento foi conduzido no laboratório do Departamento de Química e Bioquímica,IB, da UNESP, Campus de Botucatu, SP, durante o mês de fevereiro de 1998.

\section{Germinação e coleta de amostra}

Sementes selecionadas de feijoeiro Phaseolus vulgaris L. Cv. Carioca, previamente tratadas com hipoclorito de sódio comercial a $1 \%$ durante três minutos, lavadas em seguida com água destilada, foram colocadas para germinar em placas de Petri $(9 \mathrm{~cm})$ contendo duas folhas de papel de filtro Whatman $n^{0} 1$, embebidas com $10 \mathrm{~mL}$ de água destilada e em soluções teste (cádmio 1, 2, 5 e $10 \mu \mathrm{mol} \mathrm{L}^{-1}$ ). Em cada placa de Petri foram colocadas 20 sementes, sendo que a germinação ocorreu a $27^{\circ} \mathrm{C}$ no escuro. As avaliações dos cotilédones e das raízes, realizadas com três repetições e duplicatas, foram efetuadas após 24, 48, 72 e 96 horas.

\section{Atividade da peroxidase}

Extração da enzima: $1 \mathrm{~g}$ de tecido vegetal tanto de cotilédones, como de raízes, foi triturado em gral de porcelana contendo $4 \mathrm{~mL}$ de tampão fosfato de potássio $\mathrm{pH} 6,7,0,2 \mathrm{M}$. O homogenado resultante foi centrifugado 20 minutos a $10.000 \mathrm{~g}$. O sobrenadante obtido foi utilizado como fonte de enzima. Todas essas operações foram realizadas entre $0-4^{\circ} \mathrm{C}$. Sistema de reação: Foi utilizado o método descrito por Allain et al. (1974), modificado por Lima et al. (1999): $100 \mu \mathrm{mol}$ de tampão fosfato $\mathrm{pH} 6,7$; $10 \mu \mathrm{mol}$ de $\mathrm{H}_{2} \mathrm{O}_{2}$; $35 \mu \mathrm{mol}$ de fenol ; $2 \mu \mathrm{mol}$ de 4aminoantipirina e $1 \mathrm{~mL}$ de sobrenadante contendo enzima, com volume final de $2 \mathrm{~mL}$. Após permanência durante cinco minutos em banho Maria $30^{\circ} \mathrm{C}$ a reação foi interrompida com $2 \mathrm{~mL}$ de etanol absoluto e a absorbância medida a $505 \mathrm{~nm}$. A velocidade da reação foi expressa em unidades (U). Uma $\mathrm{U}$ corresponde a $1 \mu \mathrm{mol}$ de $\mathrm{H}_{2} \mathrm{O}_{2}$ consumido/minuto/mg de proteína. O teor de proteína total solúvel foi determinado através do método de Bradford (1976).

Os dados mostrados nos gráficos (atividade da peroxidase em cotilédones e raízes) representam a média de três repetições (com duplicatas), analisados pelo erro padrão (ep) $(>5 \%)(n=3)$.

\section{RESULTADOS E DISCUSSÃO}

A atividade da peroxidase nos cotilédones de feijoeiro submetidos a tratamentos com cádmio, mostrou maiores níveis quando comparados com a testemunha, a qual não apresentou grandes variações com o tempo de exposição (Figura 1). A atividade da enzima mostrou tendência de aumento nos cotilédones em função do tempo de exposição em todos os tratamentos com cádmio, exceto na última coleta para os cotilédones tratados com $10 \mu \mathrm{mol} \mathrm{L}^{-1}$ de cádmio. Este fato pode ser devido provavelmente ao efeito fitotóxico do elemento, o qual teria promovido desarranjos no desenvolvimento, na diferenciação celular no estágio juvenil e no crescimento (Singh et al., 1991), causando alterações na atividade da enzima, pois de acordo com Gaspar et al. (1986), as peroxidases podem ser usadas como marcadoras de organogênese e desenvolvimento.

Nas raízes (Figura 2), também não ocorreram variações na atividade da peroxidase no controle. Em todos os tratamentos, com exceção da aplicação das maiores doses de cádmio (5 e $10 \mu \mathrm{mol} \mathrm{L}^{-1}$ ), as raízes não mostraram variações na atividade nas primeiras horas de exposição (até 72 horas). Após esse período, isto é, com 96 horas de exposição, todos os tratamentos (com exceção do controle) promoveram aumento na atividade da peroxidase.

Resultados semelhantes foram observados por Ribeiro et al. (1995) quando estudaram o efeito do cádmio em macrófitas aquáticas. De acordo com as observações de Byl et al. (1994) a resposta da peroxidase pode ser utilizada como indicador de contaminantes do meio aquático. Chen \& Kao (1995) também verificaram aumento

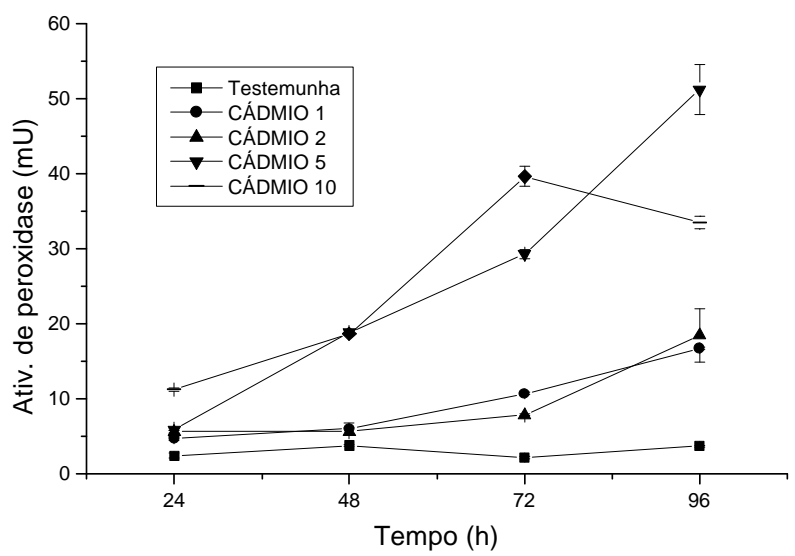

Figura 1 - Atividade da peroxidase em cotilédones de feijão cultivados sob diferentes níveis de cádmio, durante os diversos tempos de coleta. Barras verticais indicam \pm ep $(n=3)$. Botucatu, 1998.

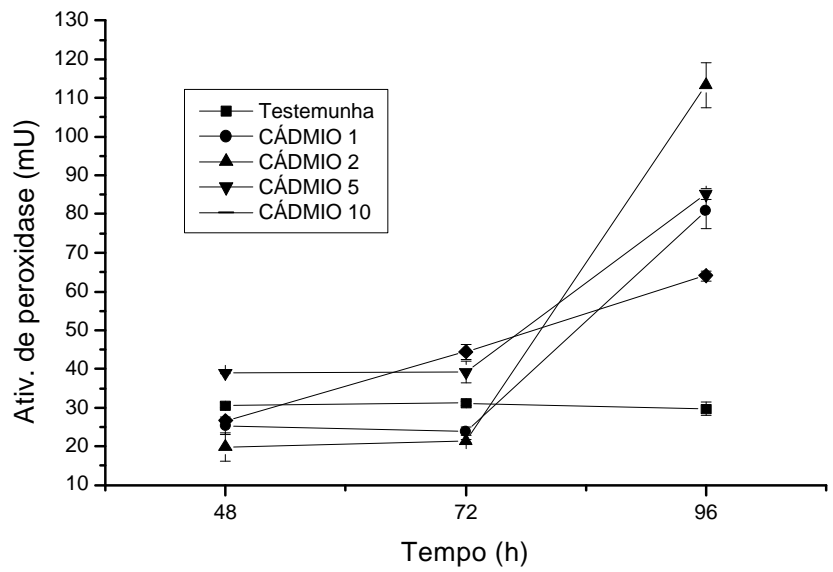

Figura 2 - Atividade da peroxidase em raízes de feijão cultivados sob diferentes níveis de cádmio, durante os diversos tempos de coleta. Barras verticais indicam $\pm \mathrm{ep}$ $(\mathrm{n}=3)$. Botucatu, 1998 
na atividade da peroxidase devido a tratamento com cádmio, quando estudaram o efeito deste metal em plântulas de arroz. Os mesmos autores mostraram que a presença de cádmio pode inibir o crescimento da raiz. Entretanto a inibição, segundo constataram mostrou-se reversível. Esta resposta também foi observada em feijoeiro por Rossi et al., 1998.

Em trabalho de revisão, Castillo (1986) afirmou que 0 cádmio pode ser um agente que promove aumento da atividade da enzima. Esse aumento pode ser provavelmente devido à síntese de novo da enzima, como sugerido por Siegel \& Galston e Galston et al. citados por Siegel (1993).

A indução da atividade da peroxidase é uma resposta das plantas em relação a elevados teores de metais tais como $\mathrm{Zn}, \mathrm{Cd}, \mathrm{Cu}, \mathrm{Ni}$ e $\mathrm{Pb}$, o que pode ser observado tanto na parte aérea como nas raízes (Tarvainen et al., 1991; Van Assche \& Clijsters, 1990). A indução da atividade da peroxidase pode ser um mecanismo utilizado pelos vegetais para reduzir os níveis de $\mathrm{H}_{2} \mathrm{O}_{2}$ e peróxidos orgânicos formados sob diferentes condições de estresse.

Assim, como o cádmio promoveu uma situação de estresse na planta estudada e a peroxidase parece ser a molécula chave de uma adaptação dos vegetais a mudanças do meio (Gaspar et al., 1986), esta enzima, como sugerido por Markkola et al. (1990) pode ser tomada como um indicador não específico de estresse causado por metais pesados.

\section{CONCLUSÃO}

A atividade da peroxidase tanto em cotilédones como em raízes de feijoeiro, de modo geral, aumentou em função das doses e do tempo de exposição ao cádmio e pode ser tomada como indicador bioquímico de estresse promovido por este metal.

\section{AGRADECIMENTOS}

À FAPESP (Proc. 96/06490/2) pelo auxílio recebido, à Auxiliar Acadêmica Vânia Aparecida de Oliveira e à Secretária do Departamento de Química e Bioquímica, Claudete Ezias Grassi.

\section{REFERÊNCIAS BIBLIOGRÁFICAS}

BRADFORD, M.M. A rapid and sensitive method for the quantitation of microgram quantities of protein utilizing the principle of protein-dye binding. Analytical Biochemistry, v.72, p.248-254, 1976.

BYL, T.D.; SUTTON, H.D.; KLAINE, S. Evaluation of peroxidase as a biochemical indicator of toxic chemical exposure in the aquatic plant Hydrilla verticillata, Royle. Environmental Toxicology and Chemistry, v.13, p.509-515, 1994.

CASTILLO, F.J. Extracellular peroxidases as markers of stress. In: GREPPIN, H.; PENEL, C.; GASPAR, TH. (Ed.) Molecular and physiological aspects of plant peroxidases. Geneva: University of Geneva, 1986. p.419-426.
CASTILLO, F.J. Peroxidases and stress. In: PENEL, C. GASPAR, T.H., GREPPIN, H. (Ed.) Plant peroxidases 19801990: topics and detailed literature of molecular, biochemical, and physiological aspects. Geneva: University of Geneva, 1992. p.187-203.

CHEN, S.L.; KAO, C.H. Cd induced changes in proline level and peroxidase activity in roots of rice seedlings. Plant Growth Regulation, v.17, p.67-71, 1995.

GASPAR, T.; PENEL, C.; CASTILLO, F.J.; GREPPIN, H. A twostep control of basic and acidic peroxidases and its significance for growth and development. Physiologia Plantarum, v.64, p.418-423, 1986.

GASPAR, T. Integrated relationships of biochemical and physiological peroxidase activities. In: GREPPIN, H.; PENEL, C.; GASPAR, T. (Ed.) Molecular and physiological aspects of plant peroxidases. Geneve: University of Geneve, 1986. p.455-468.

KVARATSKHELIA, M.; WINKEL, C.; THORNELEY, R.N.F. Purification and characterization of a novel class in peroxidase isoenzyme from tea leaves. Plant Physiology, v.114, p.1237-1245, 1997.

MARKKOLA, A.M.; OHTONEN, R.; TARVAINEN, O. Peroxidase activity as an indicator of pollution stress in the fine roots of Pinus sylvestris. Water, Air and Soil Pollution, v.52, p.149-156, 1990.

LIMA, G.P.P.; BRASIL, O.G.; OLIVEIRA, A.M. Poliaminas e atividade da peroxidase em feijão (Phaseolus vulgaris L.) cultivado sob estresse salino. Scientia Agricola, v.56, p.21-25, 1999.

PÜTTER, J. Peroxidases. In: BERGMEYER, H.V. (Ed.) Methods of enzymatic analysis. New York: Academic Press, 1965. p.688-689.

ROSSI, C.; PADILHA, P.M.; PADILHA, C.C.F. Absorção de cádmio e crescimento de feijoeiro (Phaseolus vulgaris L.) cv. carioca. Scientia Agricola, v.55, p.332-337, 1998.

RIBEIRO, M.; SALOMÃO, T.M.F.; CAMBRAIA, J. Atividade de peroxidase como bioindicador da fitotoxidade de cádmio em plantas aquáticas. In: CONGRESSO BRASILEIRO DE FISIOLOGIA VEGETAL, 5., Lavras, 1995. Resumos. Lavras: SBFV/UFLA. p.253.

SIEGEL, B.Z. Plant peroxidases: an organism perspective. Plant Growth Regulation, v.12, p. 303-312, 1993.

SINGH, T.; DEVI, S.; CHAWLA, G.; GUPTA, M.; VISWANATHAN, P.N. Ultrastructural and biochemical effects of cadmium on the aquatic Marsilea minuta Linn. Ecotoxicology and Environmental Safity, v.21, p.171-181, 1991.

TARVAINEM, O.; AHONEN-IONNARTH, V.; MARKKOLA, A.M.; VARE, $\mathrm{H}$. The influence of $\mathrm{Al}, \mathrm{Cu}$ and $\mathrm{Ni}$ on peroxidase activity in seedlings of Pinus sylvestris and migalia of Smillus variegatus. In: LOBARZEWSKI, J. GREPPIN, H.; PENEL. C. GASPAR, T. (Ed.) Biochemical, molecular and physiological aspects of plant peroxidases. Geneve: University of Geneve, 1991. p.443-445.

VAN ASSCHE, F.; CLIJSTERS, $H$. Effect of metals on enzyme activity in plants. Plant, Cell and Environment, v.3, p.195-206, 1990.

$\overline{\text { Recebido em } 15} .03 .00$ 